\title{
How is perception of being recognized by others as someone good at physics related to female and male students' physics identities?
}

\author{
Timothy J. Nokes-Malach ${ }^{1}$, Z. Yasemin Kalender ${ }^{2}$, Emily Marshman $^{3}$, Christian D. Schunn ${ }^{1}$, and Chandralekha Singh ${ }^{2}$ \\ ${ }^{1}$ Learning Research and Development Center, University of Pittsburgh, Pittsburgh PA 15260 \\ ${ }^{2}$ Department of Physics and Astronomy, University of Pittsburgh, Pittsburgh PA 15260 \\ ${ }^{3}$ Department of Physics, Community College of Allegheny County, Pittsburgh PA 15212
}

Prior research on underrepresentation of women in physics has focused on gender differences in various attitudes and beliefs students have with regards to physics. One open area of investigation pertains to the foundations of students' identities in physics, which can be a particularly powerful driver of career decisions. We present an investigation involving approximately 500 students in introductory level calculus-based physics courses, a context in which less than one third of the students are women. Students completed a motivation survey at the end of their first semester's physics course. We used Structural Equation Modeling (SEM) to test a modified physics identity framework, specifically examining whether the relation between gender and physics identity was mediated by motivational factors such as self-efficacy, interest, and perceived recognition. The results showed that students perceived recognition was a particularly important factor influencing self-efficacy and interest, which in turn mediated the relation between gender and physics identity. 


\section{INTRODUCTION}

Among the natural sciences, physics has shown the slowest progress in increasing the representation of women compared to other disciplines such as biology and chemistry [1-4]. Several interventions have been proposed to address the issue of low representation of women in physics including developing better pedagogical methods [5], improving the efficacy of physics teaching by making the curriculum relevant to all students [6], and investigating and improving students' motivational characteristics in the physics classroom [5-9].

In explaining participation in STEM careers, identity has been argued to be a particularly important motivational construct [10]. There are many forms of identity, but most relevant here is identifying with an academic domain, such as physics: students' views about whether they see themselves as a "physics person" [9-16]. Physics identity, which can shape and be shaped by students' learning experiences and classroom interactions, has been shown to predict students' career choices and outcome expectations [9-16]. Prior studies investigating students' physics identity indicate clear gender differences showing that male students are more likely to see themselves as a physics person [9], which may partially explain the gender differences to major in physics and career aspirations in physics-related fields [11-21]. Therefore, investigating the factors that influence physics identity may play an important role in understanding women's underrepresentation and their underperformance in introductory physics courses. Although there are several studies and frameworks regarding the nature of science identity generally [11-15], additional work is required to understand the motivational factors that influence women's physics identity.

We build on prior work by Hazari and colleagues in which they developed a framework for physics identity in high school by adapting the well-known science identity framework of Johnson et al. [11]. Previous studies have focused on documenting gender differences in some of the motivational factors related to physics identity such as interest in physics, beliefs about conceptual understanding of physics and performance, and perceived recognition by others $[12,13]$. However, it is not clear from the prior work to what extent these factors relate to and interact with each other and gender in calculus-based physics courses since the context of the course can be important for the relationships between these factors.

To investigate these questions, we examined students' physics identities as well as the hypothesized underlying motivational constructs within the physics identity framework. Specifically, we focused on the college-level calculus-based introductory physics courses at a large staterelated research university. Students in these classes are generally physical science or engineering majors and they are typically first year students, so this study allows us to understand their motivational characteristics early in their academic program. Typical for courses aimed at such majors, female students in calculus-based physics courses comprise approximately $30 \%$ of the class. Gendered beliefs, biases, and discrimination can negatively impact women and act as a stereotype threat against them, constraining their performance in the field. In particular, women may fear confirming the negative stereotypical beliefs about their gender in physics if they perform poorly and their anxiety can increase [22-25].

Underlying these macro-level factors (e.g., gender biases, traditional gender roles, discrimination against women), students' motivational attitudes and beliefs, which are shaped by biases and discrimination, can at least partly provide a mechanistic explanation for women's underrepresentation in STEM disciplines. Several studies in physics education have focused on students' motivational characteristics (e.g., factors such as students' interest in and value of science, beliefs about their competence, intelligence mindset views, sense of belonging and identity formation) [9,26-28]. Individual variation in these factors can impact students' learning, persistence in degree attainments, and professional career choices [28-33]. While having positive attitudes can lead to better grades on exams [33] or higher rates of retention in challenging domains [7], negative attitudes in a domain, such as low self-confidence or not feeling recognized, can lower interest, increase anxiety, and lead to disengagement from class participation [34].

Our research methodology uses quantitative methods to explore the relations between motivational factors and whether they mediate the relation between gender and physics identity. As part of this analysis, we administered a physics related motivational beliefs and attitudes survey at the end of the first physics course, a point at which students have revised their attitudes towards physics based on their first university-level experience and is also the point at which they are less likely to continue in physical sciences and engineering (i.e., it is a very consequential moment) [35].

\section{THEORETICAL BACKGROUND}

In physics, researchers have developed and validated various instruments to assess students' motivational beliefs and attitudes about learning (e.g., CLASS, MPEX) [36-49]. Investigating students' motivation in physics can provide researchers information about how students engage (or not) in learning activities and why some students persist while others do not in physics courses. Although there are several studies of gender differences in students' competency belief (or self-efficacy) [7,8,39-43] and interest $[8,39,45]$ in physics, there are relatively few studies on gender differences in other motivational constructs such as identity, which likely plays a central role in students' retention in physics [11]. Further, prior work has investigated some of these motivational factors separately, but it is not known how they relate to each other and which of them has the strongest 
relation to students' physics identities, which is central to thriving in a discipline.

\section{A. Prior relevant research on identity}

Gee's seminal framework describes identity as "the 'kind of person' one is seeking to be and enact in here and now" [50]. As an example, a physics person typically associates their physics identity with being good at physics and math or enjoying solving physics problems, which often involves applying mathematical concepts in diverse physical situations. Identity therefore is hypothesized to be influenced by motivational characteristics which can change over time with individuals' in-class and out-of-class experiences and interactions with peers, teaching assistants, and instructors in different circumstances and learning environments [11-16].

One critical question is: which motivational beliefs are central to an individual adopting a science identity [51-52]? Carlone and Johnson's science identity framework [10] includes three interrelated dimensions: competence ("I think I can"), performance ("I am able to do"), and recognition ("I am recognized by others"). They tested their science identity framework through ethnographic study to understand the science experiences of successful women in science.

Hazari et al. modified the framework by adapting it to physics specifically rather than science more generally [11]. Hazari et al.'s physics identity framework hinges on four factors: students' interest, beliefs about their competence and performance, and their views on being recognized by others [11]. Those four dimensions of the physics identity framework together make up students" "internalized" identities. Past studies have focused on the impact of physics identities on students' physics-related career choices and gender differences in high-school [11-16]. Since physics identities are influential in students' career choices and trajectories in physics-related fields, understanding how students' classroom experiences impact the motivational factors that form physics identity is vital. Below, we describe our modified framework based on these foundational theories and discuss its implications for female and male introductory physics students' physics identity.

\section{B. Theoretical model of physics identity}

We build on Hazari et al.'s physics identity framework [11]. Based on Hazari et al.'s prior empirical work showing that survey measures of performance (i.e., belief in one's ability to perform required physics tasks) and competence (i.e., belief in ability to understand physics content) did not load onto two separate factors we treat these factors as a single latent variable [53]. To describe this variable we use the more broadly-used motivational construct of selfefficacy. Self-efficacy is defined as students' beliefs in their capability to succeed in a certain situation, task, or domain [54]. Self-efficacy has been a central focus in many educational studies and predicts students' performance even after controlling for their prior knowledge [55-58]. Equally importantly, recent studies in self-efficacy have shown large gender differences in physics (i.e., female students with lower self-efficacy than male students) [7,8,39-42]. The gender gap in self-efficacy also exists when comparing similarly performing female and male students $[43,44]$. These alarming trends show that female students feel less competent in physics than male students regardless of their actual performance.

The second factor hypothesized to influence physics identity is interest [59-64]. Interest is also well paired theoretically with self-efficacy dimensions as connected constructs that predict students' academic outcome expectations and career aspirations within ExpectancyValue Theory [59]. As the third and final factor of physics identity, we investigate the recognition by others. Similar to Hazari et al. [11], we use the construct of "perceived recognition," which refers to students' perception about whether others see them as a physics person or not.

In this framework, recognition may be a particularly important driver of both identity and of self-efficacy: students' classroom experiences and interactions with instructors, course assistants and peers (which shape their perception of recognition) can in turn impact their selfefficacy to achieve and shape their class participation. In general, the motivational factors that comprise physics identity relate to and can interact with each other in meaningful ways. However, it is not clear which directions of influence are strongest and which act as pre-cursors of the others.

Based upon Bandura's theory, we test the effect of perceived recognition on self-efficacy [54]. In other words, we hypothesize that these motivational factors are intimately intertwined in that recognition by others has an effect on the other two factors, self-efficacy and interest, which have an impact on identity. We propose that these beliefs are particularly important for a domain such as physics that has strong socio-cultural biases, e.g., pertaining to a field consisting of brilliant men, and not feeling recognized might have strong effects on one's views of self-competence and interest. We also note that if we find that recognition by others or lack thereof mediates self-efficacy and interest, it may be possible to change the patterns of recognition by instructors and mentors via appropriate professional development activities.

The research reported here was conducted in the context of introductory level calculus-based physics courses. We use the Structural Equation Modeling (SEM) method to investigate the origins of gender differences in identity in calculus-based introductory physics classes in which women are underrepresented. In other words, the identity framework was used to directly test the underlying relationship of gender to identity components through a mediation model. 


\section{METHODOLOGY}

For the current study, a validated survey covering the components of the theoretical framework was administered to 559 students at the end of the semester of a calculus-based physics course. Students were enrolled in one of four different sections of introductory calculus-based physics, which is generally taken by engineering and physical science students in their first year of undergraduate studies. The university provided students' demographic information such as age, gender, ethnic/racial, and academic major information as part of a larger research study using an honest broker process. Therefore, the researchers only had access to the demographic data in this de-identified form. Note that, the gender data provided by the university records included only binary options given as "female" or "male". We understand that gender identity is a socio-cultural and nonbinary construct and can be described by multi-level categories, but here we are limited by our binary gender dataset for this study. Of the survey participants, $33 \%$ were female, and $67 \%$ were male students; one student did not have a reported gender status and was excluded from further analysis. In terms of ethnic/racial distribution, students were 77\% White, 11\% Asian, 4\% Hispanic, 3\% Black, 4\% Multiracial and $1 \%$ Other. Also, $61 \%$ of students were in an engineering track and $39 \%$ of students were majoring in the physical sciences.

We used the validated motivational surveys of identity, perceived recognition, self-efficacy, and interest based on prior instruments related to students' motivational characteristics associated with physics [8]. The scales for survey questions were adapted from existing motivational research in physics which was discussed in detail in our prior works $[8,39]$, and the validity of several of the scales examined here were reported in our previous work [8]. The prior survey validation and refinement work involved iterative use of Exploratory Factor Analysis (EFA) and oneon-one student interviews both with introductory physics and graduate level students $[8,39,43]$. Additionally, we checked the inter-reliability for the added identity items. Cronbach's alpha is a measure of internal consistency of a set of items in a measurement scale and is considered adequate when greater than 0.70 . The perceived recognition aspect of the theoretical framework relates to students' perception of how others view them as a "physics person". The survey included three separate items (Cronbach's alpha $=0.86$ ) for family, friends, TA/instructors, respectively (items such as "My family sees me as a physics person", "My friends see me as a physics person", "My physics instructor and/or TA see me as a physics person").

Each of the identity and perceived recognition items involved a four-point Likert response on the scale: Strongly Disagree, Disagree, Agree, and Strongly Agree. "I see myself as a physics person" constitutes the core internal physics identity construct and corresponds to students' beliefs and self-perception in how they designate themselves as a physics person [11].

The self-efficacy component of our framework was captured by five self-efficacy items (Cronbach's alpha = 0.83) sampling different manifestations of perceived competence in academic physics (e.g., understanding and performing in various ways). The final construct in the framework is interest, which refers to positive affect towards doing physics-related activities and being curious about the physical world [64] and was measured with five items (Cronbach's alpha $=0.86$ ). The question "In general, I find physics:" had response options "Very boring, boring, interesting, Very interesting" whereas the question "I wonder about how nature works" had temporal response options: "Never, Once a month, Once a week, Every day".

To examine whether there are gender differences in identity, we initially conducted MANOVA on students' identity, self-efficacy, interest, and recognition scores comparing female to male students. Simple Pearson correlations between constructs provided an initial validation of the proposed theoretical framework.

To provide quantitative validation test of the instruments /separability of the constructs in the current dataset, we performed a Confirmatory Factor Analysis (CFA) on identity and the identity components (perceived recognition, self-efficacy, and interest). To quantify the significance and relative strength of the hypothesized path links between gender, identity components, and physics identity with the survey data, we used Structural Equation Modeling (SEM), with a maximum likelihood estimation method vis-à-vis the lavaan package in R [65-67]. Simultaneously estimating all the model links within SEM (rather than separately with different regression models) increases the statistical power of the analysis and produces estimates for the strength of different paths within the model. We began with the saturated model and then created model variations by dropping connections or variables of low strength. In the final model, data from 517 students were included in the analysis because $7 \%$ of the initial population had some missing responses.

\section{RESULTS}

Table I shows that female students had lower scale means on physics identity with a medium effect size [68]. On average, female students' responses were close to negative range ( 2 and below is negative; female students had an average of 2.1) on the scale whereas on average male student's responses were close to positive range (positive score starts at 3.0; male students had average of 2.6) on the scale provided. All three motivational factors also showed lower scores for female students with similar effect sizes. MANOVA Wilk's Lambda test showed significant gender differences with $F(4,542)=16.70, p<0.001$.

The results of the SEM are presented visually in Figure 1. The model fit indices suggest an excellent fit to the data 
Table I. Descriptive statistics for female and male students in which $\mathrm{M}$ stands for construct mean value, SD is the standard deviation and $\mathrm{N}$ is the number of students. Effect sizes and $p$-values are presented in the right-most column and minus sign of $d$ indicates male students have higher scores than female students.

\begin{tabular}{c|cc|cc|cc}
\hline \hline & \multicolumn{2}{|c|}{$\begin{array}{c}\text { Females } \\
\mathrm{N}=182\end{array}$} & $\begin{array}{c}\text { Males } \\
\mathrm{N}=365\end{array}$ & \multicolumn{2}{|c}{ Statistics } \\
\hline \hline Construct & $M$ & $S D$ & $M$ & $S D$ & $\begin{array}{c}\text { Effect } \\
\text { Size } \\
(\mathrm{d})\end{array}$ & $p$ value \\
\hline $\begin{array}{c}\text { Physics } \\
\text { Identity }\end{array}$ & 2.1 & 0.9 & 2.6 & 0.8 & -0.6 & $<0.001$ \\
$\begin{array}{c}\text { Perceived } \\
\text { Recognition }\end{array}$ & 2.2 & 0.8 & 2.6 & 0.7 & -0.5 & $<0.001$ \\
$\begin{array}{c}\text { Self-efficacy } \\
\text { Interest }\end{array}$ & 2.6 & 0.6 & 2.9 & 0.5 & -0.6 & $<0.001$ \\
\hline \hline
\end{tabular}

(acceptable fit thresholds in parentheses): CFI $=0.942(>$ $0.90), \mathrm{TLI}=0.927(>0.90), \mathrm{RMSEA}=0.075(<0.08)$ and $\mathrm{SRMR}=0.046(<0.08)$. Figure 1 presents the standardized coefficients between each of the variables, and all were statistically significant. From a mediation perspective, it is noteworthy that when all of the predictor variables are entered in the model, the model fit with the gender variable connected directly to the physics identity gives poor fit parameters $(\mathrm{RMSEA}=0.11>0.08)$. That is, the relation between gender and physics identity (physics person) is mediated by the intervening variables that are given in our theoretical framework; female students appear to have a lower physics identity because they have lower levels of physics perceived recognition and interest which in turn strongly drive self-efficacy, which together with perceived recognition and interest strongly drive physics identity.

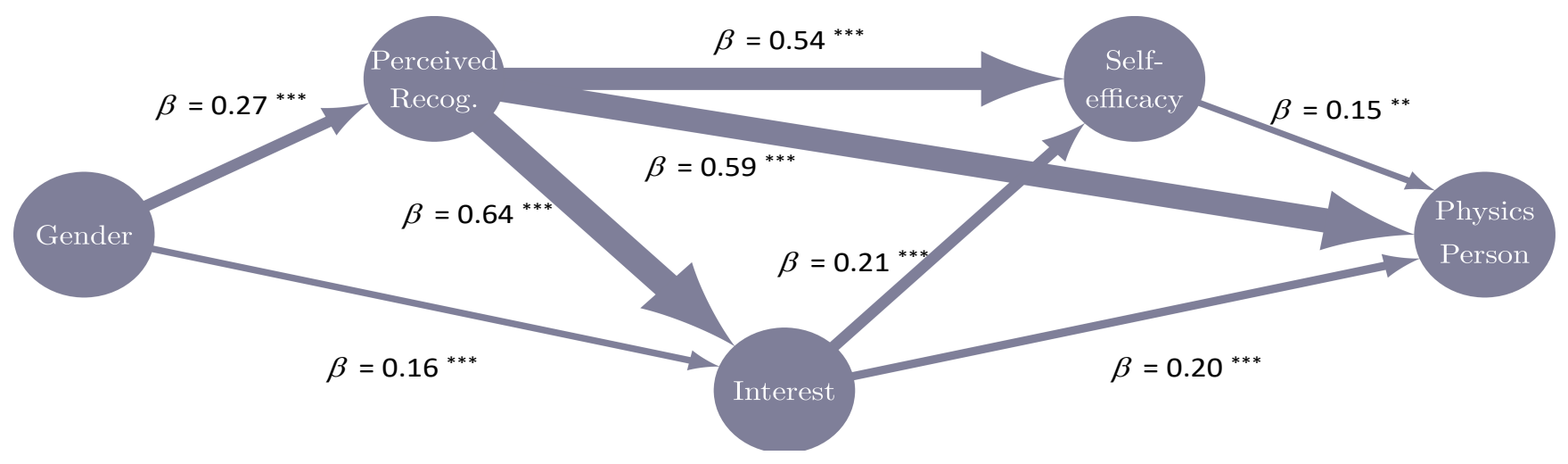

Figure 1. Results of the structural equation modeling between gender and being a physics person through self-efficacy, interest and perceived recognition. The line thickness corresponds to the magnitude of $\beta$ values; $p$-values $<0.001$ are indicated by ${ }^{* * *}$ and $p$-values $<0.01$ are indicated by ${ }^{* *}$.

\section{SUMMARY}

Using SEM, we investigated the role that motivational characteristics play in forming physics identities for male and female students in the calculus-based introductory physics classes that are recognized as gateway courses in college for physical science and engineering STEM majors and careers. One of the results is the strong effect of perceived recognition in students' other motivational beliefs (i.e., self-efficacy, interest, and identity). These results are consistent with Bandura's theory that social/verbal encouragement from others (perceived recognition) can influence self-efficacy beliefs [54] and Hidi and Renninger's interest and identity model [61]. Furthermore, students' perceived recognition exhibited a large gender gap and women' perceived recognition scores corresponded to negative attitude (i.e., women mostly disagree that others recognized them as a physics person).
These results suggest that enhancing inclusivity in the physics community and other male-dominated STEM fields can improve women's disciplinary identity and may yield benefits to women in these disciplines. Therefore, the issue surrounding the lack of diversity in physics and other science and engineering fields needs urgent action from educational researchers, practitioners, and policymakers. In this regard, fostering women's discipline-based identities in STEM can help increase the retention and advancement of talented and competent women in the STEM disciplines. These results highlight the need for improving physics learning environments.

\section{ACKNOWLEDGEMENTS}

This work was supported by grants NSF DUE-1524575 and No. 220020483 from the J. S. McDonnell Foundation. 
[1] National Student Clearinghouse Research Center (2015). Science and Engineering Degree Attainment: 20042014 , retrieved from https://nscresearchcenter.org/snapshotreportdegreeattainment $15 /$

[2] National Science Board Science and Engineering Indicators. National Science Foundation Report, retrieved from https://www.nsf.gov/statistics/2018/nsb20181/digest/sec tions/preface

[3] https://www.aip.org/statistics/data-graphics/percentphysics-bachelors-and-phds-earned-women-classes1975-through-2016

[4] Women, Minorities, and Persons with Disabilities in Science and Engineering, Occupation (2017). Retrieved from

https://nsf.gov/statistics/2017/nsf17310/digest/occupatio n/women.cfm.

[5] P. V. Engelhardt, An introduction to classical test theory as applied to conceptual multiple-choice tests, in Getting started in PER, Reviews edited by $\mathrm{C}$. Henderson and $\mathrm{K}$. A. Harper (AAPT, College Park, MD, 2009).

[6] E. Seymour, Tracking the processes of change in US undergraduate education in science, mathematics, engineering, and technology, Sci. Educ., 86, 79-105 (2001).

[7] V. Sawtelle, E. Brewe and L. Kramer, Exploring the relationship between self-efficacy and retention in introductory physics, J. Res. Sci. Teach. 49, 1096 (2012).

[8] E. Marshman, Z. Y. Kalender, C. Schunn, T. NokesMalach and C. Singh, A longitudinal analysis of students' motivational characteristics in introductory physics courses: Gender differences, Can. J. Phys. 96, 391 (2017).

[9] Z. Hazari, R. H. Tai and P. M. Sadler, Gender differences in introductory university physics performance: The influence of high school physics preparation and affective factors, Science Education 91, 847-876 (2007).

[10] H. Carlone and A. Johnson, Understanding the science experience of successful women of color: Science identity as an analytical lens, J. Res. Sci. Teach. 44(8), 1187-1218 (2007).

[11] Z. Hazari, G. Sonnert, P. Sadler and M. Shanahan, Connecting high school physics experiences, outcome expectations, physics identity, and physics career choice: A gender study, J. Res. Sci. Teach. 47(8), 978 (2010).

[12] Z. Hazari, G. Potvin, R. Lock, F. Lung, G. Sonnert and P. Sadler, Factors that affect the physical science career interest of female students: Testing five common hypotheses, Phys. Rev. ST Phys. Educ. Res. 9, 020115 (2013).

[13] Z. Hazari, P. Sadler and G. Sonnert, The science identity of college students: Exploring the intersection of gender, race, and ethnicity, J. Coll. Sci. Teach. 42(5), 82 (2013).

[14] C. Monsalve, Z. Hazari, D. McPadden, G. Sonnert and P. Sadler, Examining the relation between career outcome expectations and physics identity, Proc. 2016 Phys. Educ. Res. Conference (2016) doi:10.1119/perc.2016.pr.052.
[15] G. Potvin and Z. Hazari, The development and measurement of identity across the physical sciences, Proc. 2013 Phys. Educ. Res. Conference (2013) doi:10.1119/perc.2013.pr.058

[16] A. Godwin, G. Potvin, Z. Hazari and R. Lock, Identity, critical agency, and engineering: An affective model for predicting engineering as a career choice, Journal of Engineering Education 105(2), 312-340 (2016).

[17] E. Seymour and N.M. Hewitt, Talking About Leaving: Why Undergraduates Leave the Sciences. (Boulder, CO: Westview Press, 1997).

[18] L. Bian, S. J. Leslie and A. Chimpian, Gender stereotypes about intellectual ability emerge early and influence children's interest, Science 355(6323), 389-391 (2017).

[19] S. J. Leslie, A. Chimpian, M. Meyer and E. Freeland, Women are underrepresented in disciplines that emphasize brilliance as the key to success, Science 347, 262-265 (2015).

[20] S. Upson and L. F. Friedman, Where are the female geniuses?, Scientific American Mind 23(5), 63-65 (2012).

[21] L. Archer, J. Moote, B. Francis, J. DeWitt and L. Yeomans, The "Exceptional" physics girl: A sociological analysis of multimethod data from young women aged 10-16 to explore gendered patterns of post-16 participation, American Educational Research Journal 54(1), 88-126 (2017)

[22] C. Steele and J. Aronson, Stereotype threat and the intellectual test performance of African Americans, Attitudes and Social Cognition 69(5), 797-811 (1995).

[23] G. C. Marchand and G. Taasoobshirazi, Stereotype threat and women's performance in physics, Int. J. Sci. Educ. 35, 3050-3061 (2013).

[24] A. Maries and C. Singh, Stereotype threat? Effects of inquiring about test takers' gender on conceptual test performance in physics, AIP Conf. Proc. 1697, 1 (2015).

[25] C. Hill, C. Corbett and A. Rose, Why so few? Women in science, technology, engineering, and mathematics (2010). Retrieved from https://www.aauw.org/files/2013/02/Why-So-FewWomen-in-Science-Technology-Engineering-andMathematics.pdf.

[26] M. Wang and J. Degol, Motivational pathways to STEM career choices: using expectancy-value perspective to understand individual and gender differences in STEM fields, Dev. Rev. 33(4), 304 (2013).

[27] C. Dweck, Mindset: The New Psychology of Success (Ballentine, New York, 2006); C. Dweck, Self-theories: Their Role in Motivation, Personality, and Development (Psychology Press, Philadelphia, 1999).

[28] L. Blackwell, K. Trzesniewski, and C. Dweck, Implicit theories of intelligence predict achievement across an adolescent transition: A longitudinal study and an intervention, Child Development 78(1), 246-263 (2007).

[29] V. Tinto, Classrooms as communities: Exploring the educational character of student persistence, J. High. Educ. 68(6), 599 (1997).

[30] J. Blickenstaff, Women and science careers: Leaky pipeline or gender filter? Gender and Educ. 17, 369 (2005). 
[31] R. Ivie, and K. Stowe, Women in Physics 2000 (American Institute of Physics Rep. No. R-430) (Washington, DC, American Institute of Physics, 2000).

[32] B. Zimmerman, Self-efficacy: An essential motive to learn, Contemp. Educ. Psychol. 25, 82 (2000).

[33] P. Pintrich, A motivational science perspective on the role of student motivation in learning and teaching contexts, Journal of Educational Psychology 95(4), 667686 (2003).

[34] T. Bouffard-Bouchard, S. Parent and S. Larivee, Influence of self-efficacy on self-regulation and performance among junior and senior high-school aged students, Int. Journal of Behavioral Development 14, 153-164 (1991).

[35] W. K. Adams, K. K. Perkins, N. S. Podolefsky, M. Dubson, N. D. Finkelstein, and C. E. Wieman, New instrument for measuring student beliefs about physics and learning physics: The Colorado Learning Attitudes about Science Survey, Phys. Rev. ST PER. 2, 010101 (2006).

[36] E. Redish, J. Saul, and R. Steinberg, Student expectations in introductory physics, Am. J. Phys. 66, 212 (1998).

[37] STEM attrition: College students' paths into and out of STEM fields, Statistical Analysis Report, Retrieved from https://nces.ed.gov/pubs2014/2014001rev.pdf

[38] K. Edmondson and J. Novak, The interplay of scientific epistemological views, learning strategies, and attitudes of college students, J. Res. Sci. Teacing 30(6), 547-559 (1993).

[39] T. Nokes-Malach, E. Marshman, Z. Y. Kalender, C. Schunn and C. Singh, Investigation of male and female students' motivational characteristics throughout an introductory physics course sequence, Proceedings of the 2017 Physics Education Research Conference (2018)

[40] T. Nokes-Malach, Z. Y. Kalender, E. Marshman, C. Schunn and C. Singh, The impact of prior preparation and motivational characteristics on learning outcomes in introductory physics courses, Proc. 2018 Phys. Educ. Res. Conference (2019)

[41] J. M Nissen and J. T. Shemwell, Gender, experience, and self-efficacy in introductory physics, Phys. Rev. ST PER 12(2), 1-16 (2016).

[42] C. Lindstrøm and M. D. Sharma, Self-efficacy of first year university physics students: Do gender and prior formal instruction in physics matter? Int. J. Innovation in Sci. and Math. Educ. 19(2), 1-19 (2011).

[43] Z. Y. Kalender, E. Marshman, T. Nokes-Malach, C. Schunn and C. Singh, Large gender differences in physics self-efficacy at equal performance levels: A warning sign?, Proc. 2018 Physics Education Research Conference (2018).

[44] E. Marshman, Z. Y. Kalender, T. Nokes-Malach, C. Schunn and C. Singh, Female students with A's have similar self-efficacy as male students with C's in introductory courses: A cause for alarm?, Phys. Rev. ST. PER 14, 020123 (2018).

[45] P. Haussler and L. Hoffmann, An intervention study to enhance girls' interest, self-concept and achievement in physics class, J. Res. Sci. Teach. 39(9), 870-888 (2002).

[46] G. Kortemeyer, Correlations between student discussion behavior, attitudes, and learning, Phys. Rev. ST. PER 3, 010101 (2007).
[47] M. Lorenzo, C. Crouch and E. Mazur, Reducing gender gap in the physics classroom, Am. J. Phys. 74, 118 (2006).

[48] E. Brewe and V. Sawtelle, Modeling instruction for university physics: Examining the theory in practice, Eur. J. Phys. 39, 054001 (2018).

[49] A. Miyake, L. E. Kost-Smith, N. D. Finkelstein, S. J. Pollock and G. L. Cohen, Reducing the gender achievement gap in college science: A classroom study of values affirmation, Science 330, 1234-37 (2010).

[50] J. P. Gee, Identity as an analytical lens for research in education, Review of Research in Education 25, 99-125 (2000).

[51] J. E. Stets and P. J. Burke, A sociological approach to self and identity, Handbook of Self and Identity, 128-152 (2003).

[52] Z. Hazari, C. Cass, and C. Beattie, Obscuring power structures in the physics classroom: Linking teacher positioning, student engagement, and physics identity development, J. Res. Science Teaching 52, 735-762 (2015).

[53] R. M. Rock, Z. Hazari and G. Potvin, Physics career intentions: The effect of physics identity, math identity, and gender, Proc. 2012 Phys. Educ. Research Conference (2012).

[54] Bandura, Social cognitive theory of self-regulation, Org. Behavior and Human Decision Processes 50, 248-287 (1991).

[55] S. L. Britner and F. Pajares, Sources of science selfefficacy beliefs of middle school students, Journal of Research in Science Teaching 43, 485-499 (2006).

[56] L. Zeldin, S.L. Britner and F. Pajares, A comparative study of the self-efficacy beliefs of successful men and women in mathematics, science, and technology careers, Journal of Research in Science Teaching 45, 1036-1058 (2008).

[57] R. Lapan, A. Adams, S. Turner and J. Hinkelman, Seventh graders' vocational interest and efficacy expectation patterns, Journal of Career Development 26(3), 215 (2000).

[58] D. Schunk and F. Pajares, The development of academic self-efficacy in Development of Achievement Motivation: A Vol. in The Educ. Psychology Series, edited by A. Wigfield and J. Eccles. (San Diego, CA: Academic Press, 2002), pp. 15-31.

[59] A. Wigfield, and J. Eccles, The development of achievement task values: A theoretical analysis, Developmental Review 12, 256-310 (1992).

[60] S. Hidi, Interest: A unique motivational variable, Educational Research Review 1(2), 69 (2006).

[61] S. Hidi and K.A. Renninger, The four-phase model of interest development, J. Educ. Psychologists 41, 111 (2006).

[62] K. A. Renninger and S. Hidi, Revisiting the conceptualization, measurement and generation of interest, J. Educational Psychology, 46, 168 (2011).

[63] R. Nisbett, T. Wilson, Telling more than we can know: Verbal reports on mental processes, Psych. Rev. 84, 231 (1977).

[64] http://www.activationlab.org/tools/

[65] R. C. MacCallum, M. W. Browne and H. M. Sugawara, Power analysis and determination of sample size for 
covariance structure modeling, Psych. Methods 1, 230 (1996).

[66] D. Hooper, J. Coughlan and M. Mullen, Structural equation modeling: Guidelines for determining model fit, Electronic J. Business Research Methods 6, 53 (2008).

[67] R Core Team, $R$ : A Language and Environment for Statistical Computing, R Foundation for Statistical Computing (2013), http://www.R-project.org/.

[68] J. Cohen, Statistical Power Analysis for the Behavioral Sciences, L. Erlbaum Associates, NY (1998). 